\title{
Measurement of aerosol optical depth and sub-visual cloud detection using the optical depth sensor (ODS)
}

\author{
D. Toledo ${ }^{1}$, P. Rannou ${ }^{1}$, J.-P. Pommereau ${ }^{2}$, A. Sarkissian ${ }^{2}$, and T. Foujols ${ }^{2}$ \\ ${ }^{1}$ GSMA, UMR 7331, CNRS, Université de Reims Champagne-Ardenne, Reims, 51687, France \\ ${ }^{2}$ LATMOS, Université de Versailles-St-Quentin, Guyancourt, France \\ Correspondence to: D. Toledo (dani_toled@ hotmail.com)
}

Received: 28 May 2015 - Published in Atmos. Meas. Tech. Discuss.: 16 September 2015

Revised: 18 January 2016 - Accepted: 21 January 2016 - Published: 12 February 2016

\begin{abstract}
A small and sophisticated optical depth sensor (ODS) has been designed to work in the atmosphere of Mars. The instrument measures alternatively the diffuse radiation from the sky and the attenuated direct radiation from the Sun on the surface. The principal goals of ODS are to retrieve the daily mean aerosol optical depth (AOD) and to detect very high and optically thin clouds, crucial parameters in understanding the Martian meteorology and climatology. The detection of clouds is undertaken at twilight, allowing the detection and characterization of clouds with opacities below 0.03 (sub-visual clouds). In addition, ODS is capable to retrieve the aerosol optical depth during nighttime from moonlight measurements.

Recently, ODS has been selected at the METEO meteorological station on board the ExoMars 2018 Lander. In order to study the performance of ODS under Mars-like conditions as well as to evaluate the retrieval algorithms for terrestrial measurements, ODS was deployed in Ouagadougou (Africa) between November 2004 and October 2005, a Sahelian region characterized by its high dust aerosol load and the frequent occurrence of Saharan dust storms. The daily average AOD values retrieved by ODS were compared with those provided by a CIMEL sunphotometer of the AERONET (Aerosol Robotic NETwork) network localized at the same location. Results represent a good agreement between both ground-based instruments, with a correlation coefficient of 0.77 for the whole data set and 0.94 considering only the cloud-free days. From the whole data set, a total of 71 subvisual cirrus (SVC) were detected at twilight with opacities as thin as $1.10^{-3}$ and with a maximum of occurrence at altitudes between 14 and $20 \mathrm{~km}$. Although further optimizations and comparisons of ODS terrestrial measurements are
\end{abstract}

required, results indicate the potential of these measurements to retrieve the AOD and detect sub-visual clouds.

\section{Introduction}

Clouds play a major role in Earth's climate (i.e., Hartmann et al., 2001; Ramanathan et al., 1989). Cirrus clouds in particular, which cover a large fraction of Earth's surface $(\sim 30 \%)$, play an important role by modulating the climate system through modifications of the radiation budget of both incoming solar radiation and outgoing infrared radiation. They scatter the solar radiation in the visible back to space (the albedo effect) and absorb and re-emit infrared terrestrial radiation to space (the greenhouse effect). However, the cirrus cloud climate effect is very complex (Liou, 1986) since it depends, among other parameters, on cloud optical properties. Unlike other clouds, thin cirrus clouds, such as sub-visual cirrus (SVC), result in a net positive radiative forcing in the atmosphere (McFarquhar et al., 2000; Wang et al., 1996). These clouds are very cold, of temperatures around or below $-80^{\circ} \mathrm{C}$, and made of much smaller ice particles than typical cirrus clouds. Because of their cold temperatures, they are optically thin in shortwave radiation. However, they readily absorb the outgoing longwave radiation, thereby contributing to the greenhouse effect. In addition, SVCs located near the tropical tropopause play a key role in the dehydration of the upper troposphere-lower stratosphere (UTLS) (Jensen et al., 2013). Although SVCs mostly occur in the tropical tropopause region, they have been also observed at midlatitudes. SVCs are identified as one of the largest sources of uncertainty in the study of Earth's radiation budget (Lynch et 


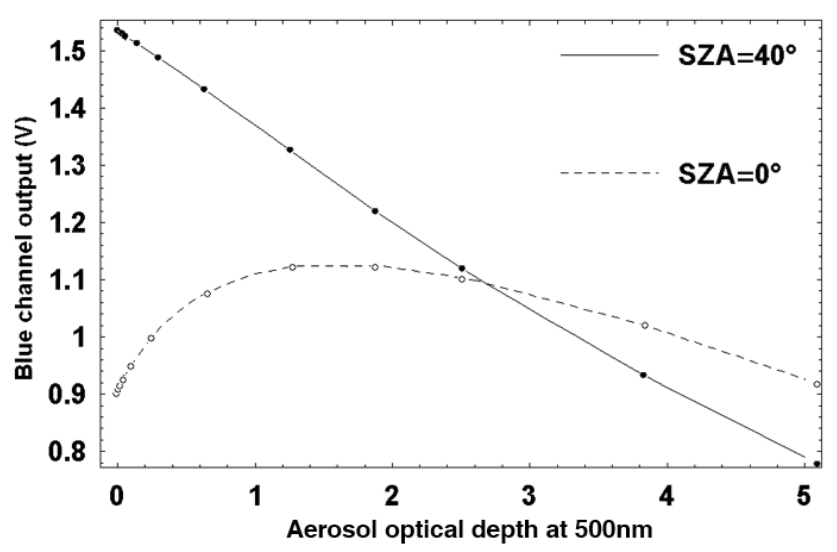

Figure 1. Solar flux received by ODS in the blue wavelength range as a function of the aerosol optical depth (AOD), at $40^{\circ} \mathrm{SZA}$ (solid line with black circles) for total direct and scattered sunlight and at $0^{\circ} \mathrm{SZA}$ (dashed line with white circles) for scattered sunlight only. The ratio between the two fluxes varies monotonously, with AOD providing a direct AOD measurement independent of sensor calibration.

al., 2002), largely because of the difficulty of their detection and the lack of knowledge about their optical properties. Due to their very small optical depth, SVCs can be detected by solar occultation measurements only, and hence further studies of the occurrence and optical properties of these clouds are needed.

Another important contributor to atmospheric radiation energy balance and climate forcing is the tropospheric dust aerosols. Depending on dust particle size and their vertical distribution, the net radiative forcing in the upper troposphere-lower stratosphere (UTLS) can be either positive (warming) or negative (cooling) (Jacobson, 2001; Miller and Tegen, 1998; Tegen et al., 1996). Furthermore, there is evidence of indirect effect of dust, acting as ice nuclei in cloud microphysics and optical properties (Sassen, 2002).

The goal of the paper is the description of a small optical depth sensor (ODS), designed to retrieve the daily average aerosol optical depth (AOD) and detect as well as characterize high clouds on Earth and Mars from ground-based observations. The performance of the terrestrial prototype of ODS was evaluated during a test campaign in Ouagadougou, a desert environment in the Sahelian region of Burkina Faso in western Africa. We present here the main concept of the instrument; the retrieval procedures which were adopted to analyze the ODS signals; and the results of long series of measurements carried out between November 2004 and October 2005, including comparisons with AERONET (Aerosol Robotic NETwork) AOD measurements.

\section{Instrumentation}

\subsection{Principle of measurements}

ODS is designed to make daytime alternative observations of the scattered sunlight at zenith and the sum of the direct and scattered sunlight in the blue and red wavelength ranges. Figure 1 shows the ODS blue-channel output (in volts) as a function of AOD for two different solar zenith angles (SZAs). Direct and scattered sunlight is received by $\mathrm{ODS}$ for $\mathrm{SZA}=40^{\circ}$, whereas for $\mathrm{SZA}=0^{\circ}$ the instrument only receives scattered light. The ratio between the scattered sunlight at zenith and the sum of the direct and scattered sunlight decreases monotonously at increasing AOD, providing an AOD measurement independent of the sensor calibration. Since the high clouds imply a sky reddening during twilight, they can be detected by looking at the evolution of the color index (CI), defined as the ratio between red and blue channels, at SZAs between 90 and $95^{\circ}$. Because of the wavelength dependence of Rayleigh scattering, the altitude of the mean scattering layer is higher in blue than in red, hence producing a greater attenuation of direct sunlight, implying a sky reddening at twilight. In addition, the shape and SZA of the peak CI reddening depends on the cloud optical depth (COD). This method for deriving cloud altitude from CI observations is very similar to that developed for polar stratospheric clouds (Sarkissian et al., 1991). It allows detecting optically thin clouds, since the pathway of sunlight in a horizontally homogeneous cloud of $\Delta h$ geometrical thickness is enhanced by a factor 200 at $90^{\circ} \mathrm{SZA}$.

\subsection{ODS instrument}

The ODS instrument used in this work is a lightweight optical instrument looking at zenith (Maria et al., 2006; Trân et al., 2005). ODS is designed for AOD retrieval both in blue and red as well as for detecting clouds during morning and evening twilights. It is made of two identical optical heads, each making use of two parabolic mirrors facing each other and surrounded by black walls, a central mask avoiding direct sun entry and a silicon photodiode (left of Fig. 2). Only rays entering the entrance pupil (F1) at zenith angles between 25 and $50^{\circ}$ are reflected by the parabolic mirrors (black arrows) and then focused on the photodiode at the F2 focal point. Other rays are absorbed by the central mask or by the black walls. This design defines an annular field of view (FOV) shown on the right of Fig. 2. Through this FOV configuration, this instrument measures the scattered light from the atmosphere and, additionally when the sun is within the FOV, direct light. The same observations are carried out during the night when the moon trajectory crosses the FOV of ODS.

Blue and red channels are selected by using colored glass filters placed in front of the photodiodes. The only differences between the two ODS heads are the filters in front of the detectors: two filters resulting in a band-pass filter of 

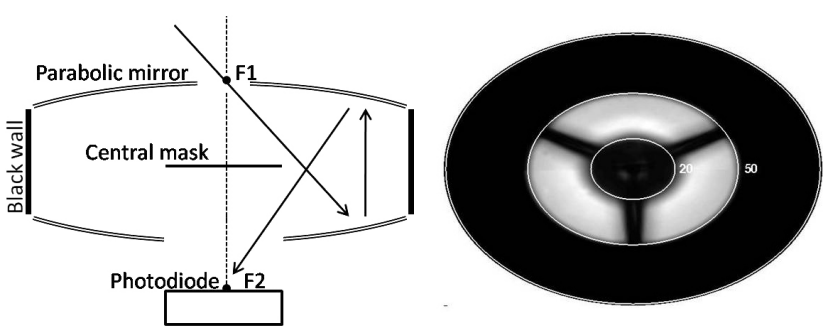

Figure 2. ODS optical head (on the left) made by two parabolic mirrors surrounded by black walls to avoid unwanted reflections, a central mask supported by 3 small legs and a photodiode. Rays entering the entrance hole at the focal point F1 (black arrows), are reflected by the parabolic mirrors and focused on the photodiode focal point F2. Right: measured ODS field of view. White and black areas correspond to 100 and $0 \%$ of transmission, respectively. Most light is collected between 25 and $50^{\circ}$.

$365 \mathrm{~nm}$ for the blue channel, and a high-pass filter is used with a cutoff at $775 \mathrm{~nm}$ for the red channel (Fig. 3a). By combining the spectral response of the filters and the photodiode (Fig. 3c) with the solar spectral irradiance on Earth's surface (Fig. 3d), we found that the effective wavelengths of the blue and red ODS channels are 370 and $902 \mathrm{~nm}$, respectively. The spectral range of the photodiode (Fig. 3b) allows measurements over a large range of AOD values, whose signal is amplified by an 8-decade logarithmic amplifier, converting photodiode current to output voltage. The output voltage is linearly dependent on the logarithm of the current, whose electronic output function can be approximated by

$O=0.86 \times \log _{10}(i)+6.28$,

where $O$ is the output voltage and $i$ the current in ampere. Unique characteristics of ODS are the use of a logarithmic amplifier allowing measurements in a large range of irradiances spanning from direct sun illumination to scattered moonlight at night. In addition, the instrument temperature variations are compensated electronically, making ODS measurements insensitive to temperature drifts.

Finally, the measurements frequency can be adapted to data transmission requirements. In the present case the sampling frequency is one measurement for both channels every $10 \mathrm{~s}$.

\subsection{AERONET}

For evaluating the accuracy of the retrieval procedure, the ODS blue-channel AODs were compared to those provided by the AERONET CIMEL instrument operating in Ouagadougou. The AERONET (Holben et al., 1998) program is a network of globally distributed ground-based automated radiometers whose objective is to retrieve the aerosol optical properties in key locations on the basis of spectral measurements of solar and sky radiation. The AERONET CIMEL operating in Ouagadougou provided measurements of aerosol

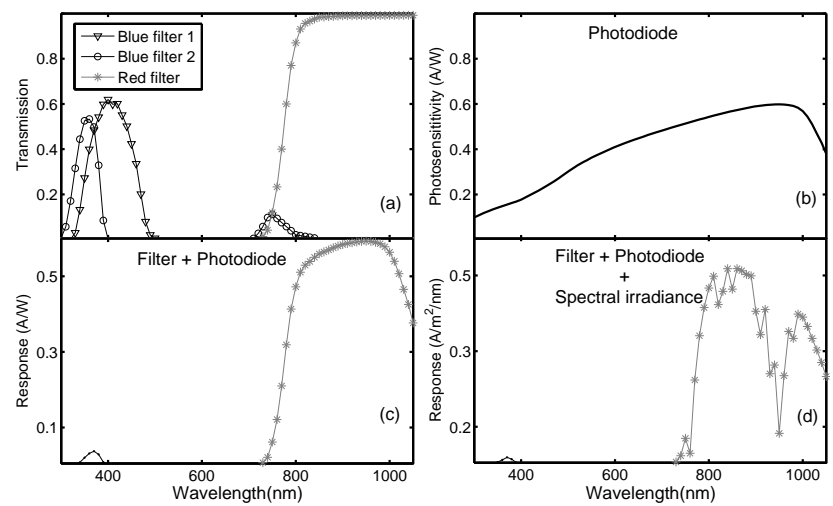

Figure 3. (a) Blue- and red-filter transmission. (b) Photodiode spectral response. (c) Response of filters-photodiodes combination. (d) Final blue-channel response $(370 \mu \mathrm{m} \pm 20 \mu \mathrm{m})$ on the left and red-channel response $(902 \mu \mathrm{m} \pm 169 \mu \mathrm{m})$ on the right.

optical depth at $440,675,870$ and $1020 \mathrm{~nm}$ wavelengths as well as the spectral single-scattering albedo and size distribution of aerosol (Dubovik and King, 2000).

\section{ODS measurements in Ouagadougou}

\subsection{Ouagadougou field campaign}

Since one of the goals was the characterization of the sensor performance in view of future flight to Mars, a Marslike desert location was sought for validation purposes. ODS measurements were performed in Ouagadougou $\left(12.4^{\circ} \mathrm{N}\right.$, $1.5^{\circ} \mathrm{W}$ ) in Burkina Faso in western Africa, a Sahelian region characterized by its high-aerosol-loading conditions and the frequent occurrence of dust storms (Hsu et al., 1999). In addition, biomass burning is frequently advected by the monsoon from western Africa (Hao and Liu, 1994), following a seasonal cycle that peaks during the dry season. Low AOD values might also occur during the rainy season (from May to September) as a result of aerosol particle removal due to heavy precipitation. A major advantage of this key location was the presence of a CIMEL sunphotometer of the AERONET network (http://aeronet.gsfc.nasa.gov) to test the AOD retrieval procedure for the terrestrial prototype of ODS. In addition, since Ouagadougou is within the tropical belt, this location is also characterized by the presence of SVC in the UTLS as reported by satellites measurements.

\subsection{ODS measurements}

Figure 4 shows an example of the evolution of ODS signals (blue and red channels) during a cloud-free day, 23 December 2004, in Ouagadougou. The bands delimited by vertical dashed lines represent the time intervals during which the sun is within the ODS FOV. The ODS signals throughout the day can be divided into three time intervals according to 


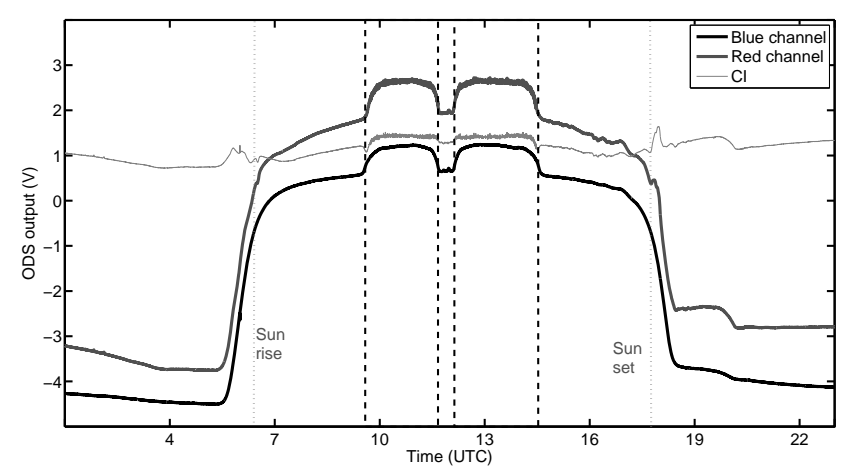

Figure 4. ODS measurement in Ouagadougou on 23 December 2004 in cloud-free conditions. The bands delimited by the black dashed lines represent the time intervals for which the sun is within the FOV of ODS.

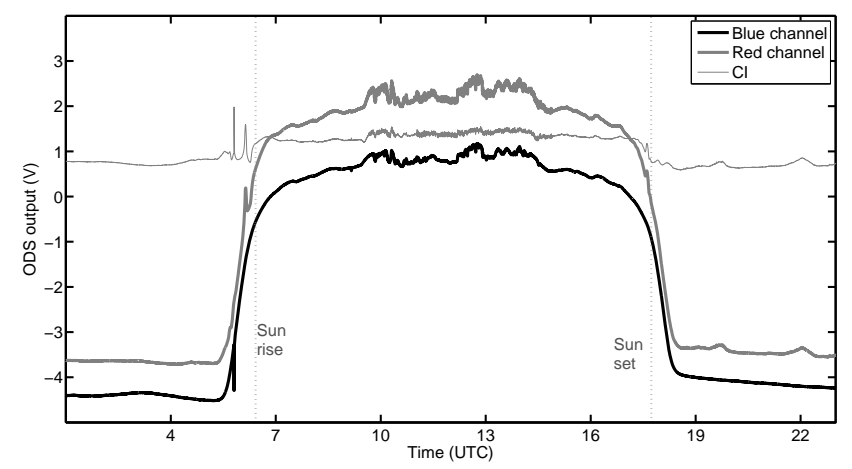

Figure 5. Same as Fig. 4 but on a fully overcast day.

ODS signal time variation: the first (06:00-06:40 and 17:2018:00 UTC) is characterized by a rapid increase with the time, the second (06:40-09:30 and 15:30-17:20 UTC) corresponds to a lower increase with the time with respect to the previous segment, and the third (09:30-12:00 and 12:0014:30 UTC) shows once again a rapid increase of ODS signals and subsequently a decrease. Since one of the branches supporting the central mask is oriented towards the south, the evolution during the afternoon is almost symmetric. In the third segment, the sun crosses the FOV of ODS, increasing the flux received by the instrument. Subsequently, the detector is shadowed by a branch supporting the central mask, dropping the ODS signal. In contrast, there were some overcast days for which the analysis of ODS signal is not possible. One of those days is illustrated in Fig. 5. Although the sun crosses the FOV of ODS between 10:00 and 15:00 UTC, we do not observe an appreciable increase of ODS signals for that time interval. Fully overcast days are then ignored in the analysis. In addition, similar features to those shown in Fig. 4 can be seen often during nighttime when the moon is passing in the ODS FOV. Figure 6 shows one of those days from which the AOD can be also retrieved. However, because of the color of the moonlight, the ratio between scat-

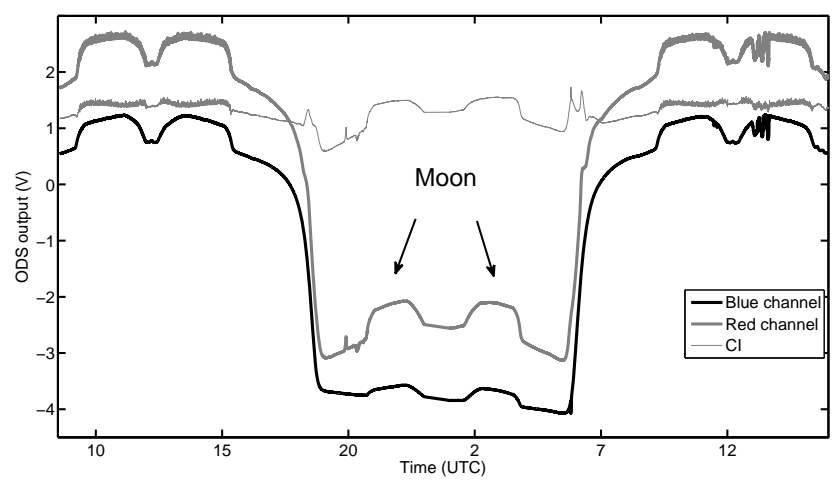

Figure 6. Moonlight ODS measurements in Ouagadougou on 2324 February 2005.

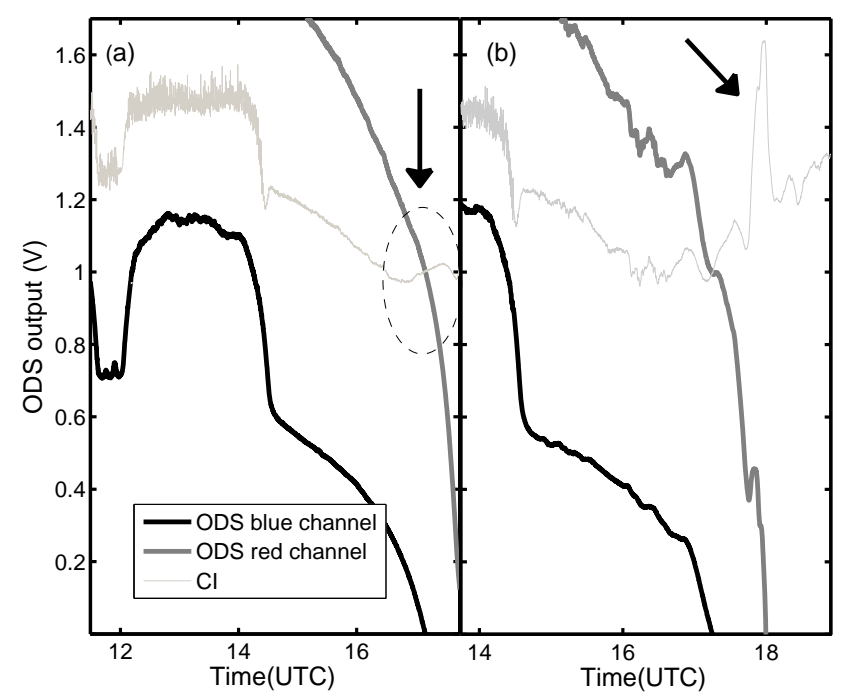

Figure 7. Evolution of ODS signals during sunset on a clear day (a) and slightly cloudy day (b).

tered and direct moonlight is smaller in the blue than in the red. Unique nighttime AOD measurements are then available during moon periods, allowing investigation of the AOD diurnal cycle.

In order to identify the peaks in the CI evolution produced by SVC, Fig. 7 shows the CI variation during sunset for a clear (a) and a slightly overcast (b) day. Different maxima in the evolution of CI can be observed in both figures. However, only the maximum in the CI delimited by the black circle (Fig. 7a) is caused by the reddening of the sky due to thin high cirrus clouds. The maxima in the CI observed in Fig. 7b are produced by the presence of thick clouds within the ODS FOV which imply fast variations in both ODS signals. Therefore, only the cloud-free days as in Fig. 7a for which a peak $\mathrm{CI}$ is observed at SZAs ranging between 90 and $95^{\circ}$ are selected for the cloud analysis. 


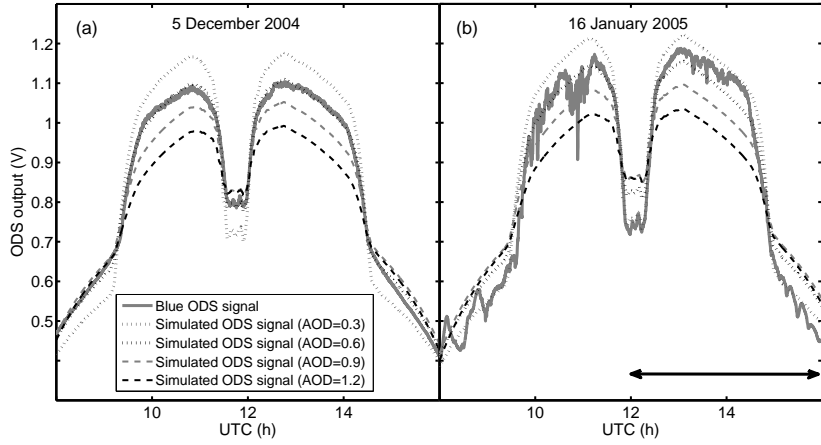

Figure 8. Comparison between ODS blue channel observed output voltage and simulated blue ODS signal for AOD values of $0.1,0.6$ and 1 (a) in cloud-free conditions on 5 December 2004 and (b) on 16 January 2005 in cloudy conditions.

\subsection{AOD retrieval procedure}

The AOD is estimated by simulating ODS signal throughout the day, through radiative transfer simulations. The photodiode current is calculated by

$$
\begin{aligned}
i= & S_{\text {pupil }} \int_{0}^{\infty} T_{\text {fiter }}(\lambda) R_{\text {diode }}(\lambda) T_{\text {mask }}\left(\mu_{0}, \varphi_{0}, \lambda\right) \\
& \mu_{0} \Phi \exp \left(-\tau / \mu_{0}\right) d \lambda+S_{\text {pupil }} \int_{0}^{\infty} \int_{0}^{2 \pi} \int_{-1}^{0} I\left(\tau, \mu_{0}, \mu, \varphi, \lambda\right) \\
& T_{\text {filter }}(\lambda) R_{\text {diode }}(\lambda) T_{\text {mask }}(\mu, \phi, \lambda) \mu d \mu d \varphi d \lambda,
\end{aligned}
$$

where $I$ is scattered intensity calculated by the radiative transfer model; $\mu_{0}, \mu$ and $\varphi$ are the cosine of SZA, cosine of observation zenith angle and azimuth angle, respectively; $T_{\text {mask }}, T_{\text {filter }}, R_{\text {diode }}(\mathrm{A} / \mathrm{W}$ ) and $\Phi$ are the mask transmission, the filter transmission, the spectral response of photodiode and the solar flux, respectively (Fig. 3); $\tau$ is the total vertical opacity; $S_{\text {pupil }}$ is the area of the pupil; and $\lambda$ is the wavelength. The first term on the right side of Eq. (2) corresponds to the contribution of direct sunlight. Finally, the conversion of ODS photodiode current into output voltage $(V)$ is done using Eq. (1). Figure 8 shows the evolution of ODS blue signal for two different days and those simulated for different AOD values. As seen on Fig. 8, the ratio between scattered flux and total scattered and direct sunlight highly depends on the AOD. Therefore, given an ODS signal, we can provide an AOD relative measurement independent of instrument calibration by searching for the optimal value of this parameter that provides the best fit between observations and simulations. In the present case, the AOD is 0.6 on 5 December 2004 and 0.45 on 16 January 2005. The major difference between these days is the presence of clouds within the ODS FOV in Fig. 8b, implying fast variations. Since such variations introduce errors in the estimation of AOD, they must be removed from the signal before the analysis. The identification of ODS observations affected by the presence of clouds is carried out in different steps. Firstly, the daily average AOD is derived by doing a best fit between observations and simulations. Subsequently, we calculate the squared difference between observations and the ODS signal simulated using the AOD retrieved in the previous step. By comparing the time variation of these differences with those obtained under variations of AOD, we can identify the observations affected by the presence of clouds. Once these observations are removed from ODS signal, the final AOD value is estimated using the filtered signal. Since fewer observations are used in the retrieval procedure to estimate the AOD, the first consequence of the cloudy days is an increase of the errors in the estimation of this parameter.

Since radiative transfer simulations take a long time to calculate, the retrieval procedure makes use of a pre-computed set of look-up tables (LUTs), for minimizing the mean square difference between simulated and observed ODS signals. In addition, an uncertainty is provided by the square of diagonal elements of elements of the parameter covariance matrix.

$\sigma=\sqrt{\operatorname{diag}\left(\left[\mathbf{J}^{T} \mathbf{W} \mathbf{J}\right]^{-1}\right)}$,

where $\mathbf{J}$ is the Jacobian matrix and $\mathbf{W}$ a diagonal matrix with $W_{i i}=\frac{1}{w_{i}}$ entries, with $w_{i}$ being the error associated with measurement $y_{i}$.

According to Dubovik et al. (2002), the size distribution of desert dust is always bimodal and dominated by large particles. Therefore, following their prescription, we assume two modes (coarse and fine modes) to calculate the phase function in our model, and the ratio between both modes (RM) is treated as a free parameter. The phase function is derived from the empirical formulation proposed by Pollack and Cuzzi (1980), using the effective radius and effective variance provided in Dubovik et al. (2002). Figure 9a shows, as an example, the phase functions calculated by the method of Pollack and Cuzzi for two different RM values. The singlescattering albedo $(\omega)$ is taken from Dubovik et al. (2002).

It is assumed that scattering and absorption aerosol coefficients decrease exponentially with altitude with a scale height of $8000 \mathrm{~m}$. The scale height does not have a major impact on the retrieval since, as said below, the radiative transfer simulations are carried out in plane-parallel geometry. Retrieved parameters are the AOD and the ratio between coarse and fine modes of size distributions. The intensity field is computed for a dense grid of SZA, looking up zenith angle (LZA), and azimuth angles $\left(\triangle \mathrm{SZA}=\Delta \mathrm{LZA}=\Delta \varphi=1^{\circ}\right.$ for the range $0-80,0-90$ and $\left.0-360^{\circ}\right)$. The intensity field is calculated for 15 AOD values $(0.01,0.03,0.05,0.07,0.09,0.1$, $0.3,0.5,0.7,0.9,1,3,5,7$ and 9$)$ and $4 \mathrm{RM}$ values $\left(1 \times 10^{-4}\right.$, $1 \times 10^{-3}, 1 \times 10^{-2}$ and $\left.1 \times 10^{-1}\right)$. A linear interpolation is used to derive intensity field functions for the required AOD and RM values. We found that for the size of the AOD grid an arithmetic step within each decade is a good arrangement. 

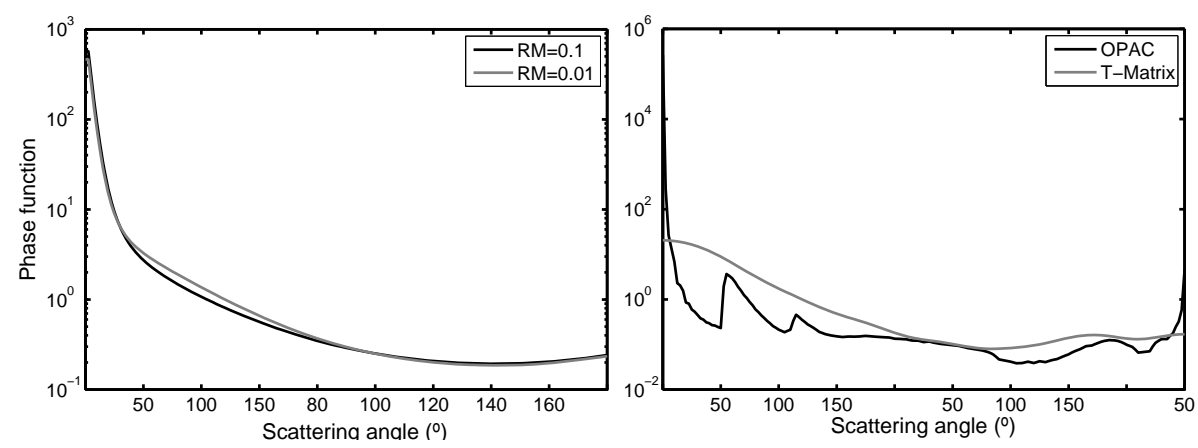

Figure 9. (a) Phase functions at $370 \mathrm{~nm}$ calculated by the empirical formulation proposed by Pollack and Cuzzi assuming a bimodal size distribution. The phase functions are calculated for two different ratios between modes. (b) Phase functions at $902 \mathrm{~nm}$ derived from the OPAC software and T-matrix method for cloud particles.

Since radiative transfer calculations are undertaken at SZAs between 0 and $80^{\circ}$, the intensity field is computed by using the spherical harmonics discrete-ordinate method (SHDOM) (Evans, 1998), which is a one-dimensional radiative transfer model in plane-parallel geometry. For testing the reliability of calculations, first the radiance simulated by the SHDOM code was compared against the DISORT plane-parallel radiative transfer code (Stammes et al., 1988) and using different values of the number of streams. These comparisons were carried out for a total opacity of 0.5 , a single-scattering albedo of 0.8 and different phase functions. In order to check the plane-parallel approximation, these simulations were carried out for $\mathrm{SZA}=0^{\circ}$. We obtained the same results using both codes, and the simulations demonstrated the need of using at least 16 streams in the calculations. Subsequently, SHDOM calculations were compared against a tested Monte Carlo radiative transfer code in spherical geometry (Trân, 2005) for SZAs between 0 and $90^{\circ}$. The results showed the reliability of SHDOM simulations at SZAs between 0 and $80^{\circ}$ (Toledo, 2015).

\subsection{Cloud property retrieval procedure}

As for AOD, cloud parameters are derived from the simulations of ODS signals. In this case, however, the simulations are undertaken for the red channel at twilight and as a function of the altitude and optical depth of the cloud. The AOD is a well-defined parameter in the simulations, since its impact on the ODS signal is well known. The color index is then defined as the ratio of modeled red ODS signal and the observed blue ODS signal. Although ODS is a well-suited instrument for the detection of thin cirrus clouds at twilight, measurements of their properties present several challenges for radiative transfer modeling. Firstly, twilight simulations require the use of a radiative transfer model that accounts for multiple scattering in spherical geometry since the plane-parallel geometry approximation breaks down for high SZA. In this work we use a three-dimensional Monte Carlo radiative transfer model (Trân, 2005) in spherical ge- ometry (referred to hereafter as the 3-D-MC). Secondly, cirrus properties are highly variable, both in time and space, which is valid for ice particle size distribution and shape, as well as optical properties such as the cloud particle phase function. Recent in situ measurements (Jensen et al., 2008; Lawson et al., 2008) have shown the presence of sub-visual cirrus clouds containing much larger ice crystals, with sizes of up to $100 \mu \mathrm{m}$, compared to earlier measurements (Heymsfield, 1986). In addition, there is a wide range of ice crystal shapes, since the shape of the ice particles depends on the conditions in which cirrus clouds form. In situ measurements have reported crystals with quasi-spherical and hexagonal symmetries such as hexagonal plates and columns, as well as crystals with rosette shapes. Since it is not possible to model all the details of cirrus clouds, we investigated the sensitivity of the ODS signal to ice crystal optical properties. ODS signals were simulated by using different phase functions obtained from the Optical Properties of Aerosol and Clouds software (OPAC) (Hess et al., 1998) and T-matrix method (Mishchenko and Travis, 1994; Mishchenko, 1991) for the study (Fig. 9b). The phase functions obtained from OPAC correspond to mixtures of columnar ice crystals of different sizes and aspect ratios randomly orientated, while those calculated by using T-matrix correspond to spheroids of different aspect ratios, randomly oriented. A variety of ODS simulations have been performed by changing the phase function of ice particles for a cloud located at $15 \mathrm{~km}$ and of $\mathrm{COD}=0.02$. The cloud geometrical thickness was fixed at $1 \mathrm{~km}$, and the cloud spatial distribution density defined by a Gaussian height profile, scaled to produce a $\mathrm{COD}=0.02$. The ODS signal simulations for those phase functions showed that cloud particles shape and size distribution have little impact on ODS retrievals. This result is due to fact that, even if the intensities may change with the phase function, the CI remains identical since it is a relative measurement of the intensity in both wavelengths. A linear regression was applied between the two simulated ODS signals for the two different phases functions, providing a coefficient of determination $\left(r^{2}\right)$ of 0.999 . Since the 
cloud geometrical thickness can modify the intensity field at twilight, a similar sensitivity analysis of ODS signal was performed. The ODS signal was simulated for a cloud at $15 \mathrm{~km}$ with a $\mathrm{COD}=0.02$, using a geometrical thickness of $\Delta h=600 \mathrm{~m}$, then set to $\Delta h=1000 \mathrm{~m}$ and to $\Delta h=1400 \mathrm{~m}$. A coefficient of determination of 0.997 was obtained for the simulated ODS signals for $\Delta h=600 \mathrm{~m}$ and $\Delta h=1400 \mathrm{~m}$, which indicates that the geometrical thickness of the cloud is not a major parameter in the retrievals. Finally, similar cloud simulations have been performed using three different surface albedo values, resulting in a determination coefficient $r^{2}=0.998$ between the ODS signals using a surface albedo $a=0$ and $a=0.4$. Results demonstrate that these parameters are of little impact on ODS simulations at twilight and that the shape of the peak CI as well as the SZA of maximum $\mathrm{CI}$ are mainly dependent of cloud altitude and opacity. An example of sunset ODS CI variation is illustrated in Fig. 10, where a maximum reddening can be observed around a SZA of $93.5^{\circ}$. Figure 10 also shows the evolution of different CI signals simulated by the 3 -D-MC model for $\mathrm{COD}=0.004$ and 0.04 , and cloud altitudes $h=8,12$ and $15 \mathrm{~km}$. Note that the shape of the CI signal strongly depends on cloud altitude and optical depth. Moreover, the SZA of maximum CI depends also on these parameters. Once a high cloud is detected by ODS, its altitude and optical depth can be estimated by searching for the optimal values of these parameters that provide the best fit between simulated and ODS-measured signals.

The retrieval procedure for cloud properties is also based on the use of LUTs. LUTs were generated using 1800 SZAs from 84.9 to $95.9^{\circ}$, at the same LZA and azimuth angles used for AOD; 4 COD values (0, 0.008, 0.02 and 0.08); 13 cloud altitudes $(8,9,10,11,12,13,14,15,16,17,18,19$ and $20 \mathrm{~km})$; and 5 AOD values $(0,0.02,0.12,0.25$ and 0.60$)$. Higher values of the AOD are not considered in the simulations since in such cases the impact of high clouds on the red ODS signal is totally masked by the dust. A linear interpolation is used to derive intensity field functions for required COD and angles of observation. The reliability of COD linear interpolation is investigated by comparing CI derived from LUT linear interpolation to those of the simulations. Two examples of comparisons are shown in Fig. 11. They indicate that the linear interpolation technique and the COD LUT size grid are adequate to simulate CI variations for required COD and observations angles. However, because the SZA of maximum CI depends on cloud altitude (see Fig. 10), a linear interpolation of cloud altitude cannot be used to search for the optimal cloud parameters values. In summary, once a high cloud is detected by ODS, a COD optimal value is calculated for each cloud altitude $h_{n}$ in the LUT grid by searching for the minimum of $\chi^{2}$, with $n=1,2 \ldots, 13$ and $h_{1}=8 \mathrm{~km}, h_{2}=9 \mathrm{~km}, \ldots, h_{13}=20 \mathrm{~km}$. A total of 13 best-fit COD values of different $\chi^{2}$ are obtained for each cloud detected. The altitude of the cloud is the altitude $h_{n^{*}}$ of the LUT grid that provides the fit of minimum $\chi^{2}$.

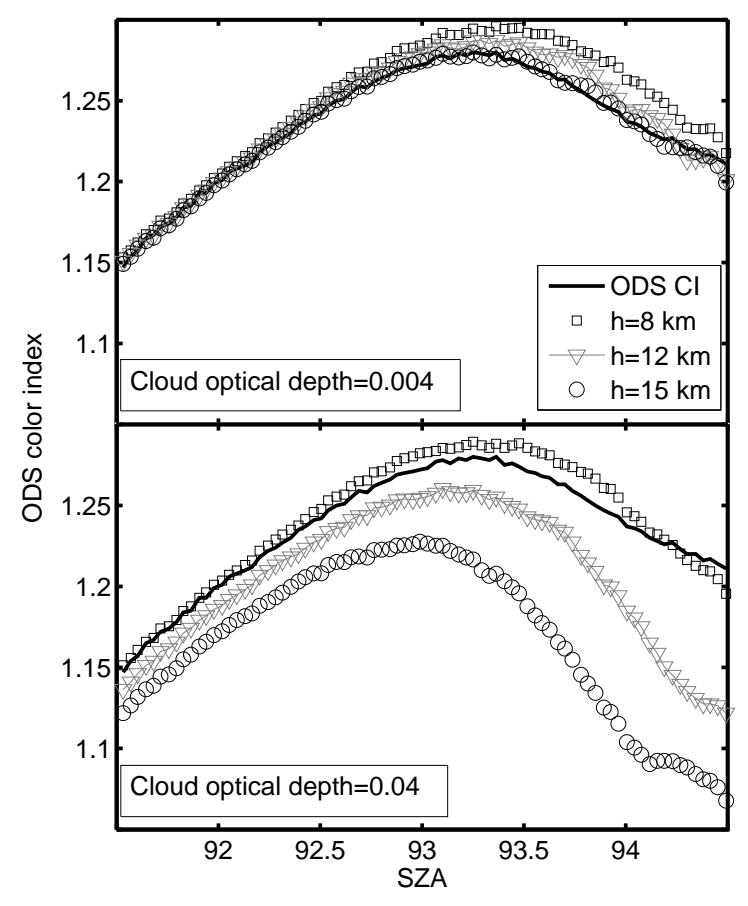

Figure 10. (a) ODS color index (black solid line) during sunset for one day of the campaign and simulated color index for $\mathrm{COD}=$ 0.004 and cloud altitude $h=8,12$ and $15 \mathrm{~km}$. (b) Same as (a) but for $\mathrm{COD}=0.04$. The simulated CI for $\mathrm{COD}=0.004$ and $h=15 \mathrm{~km}$ fits better with the ODS-measured CI.

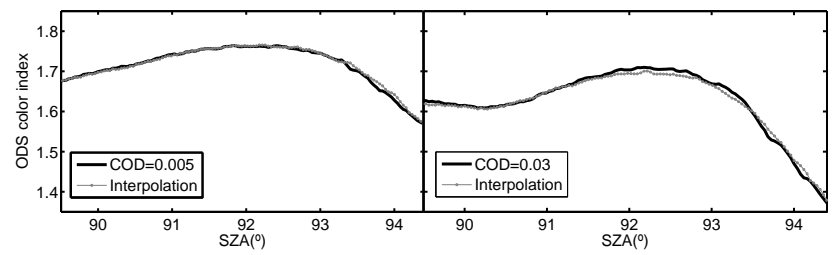

Figure 11. ODS color index for $\mathrm{COD}=0.005$ and 0.03 , and a cloud altitude $h=12 \mathrm{~km}$ interpolated (grey circles) from pre-calculated LUT COD and the ODS color index (black solid lines) simulated by the Monte Carlo model.

Figure 12a shows the distribution of $\chi^{2}$ with the cloud altitude $h$ for a SVC detected on 18 January 2005. $\chi^{2}$ is a convex function of cloud altitude, where in this example the minimum $\chi^{2}$ is at $h_{9}=16 \mathrm{~km}$ and hence $n^{*}=9$. The error associated with the cloud altitude is $h_{ \pm}$, which satisfies $\chi^{2}\left(h_{ \pm}\right)=2^{*} \chi_{\min }^{2}$. However, because the $\chi^{2}$ distribution is only known for a limited number of cloud levels, the $\chi^{2}$ distribution near the minimum is approximated by a quadratic polynomial function. By using three altitudes $\left(h_{n^{*}-1}, h_{n^{*}}\right.$ and $h_{n^{*}+1}$ ) as well as the evaluation of $\chi^{2}$ at these altitudes, we can calculate the quadratic polynomial function that goes through these points, and hence the cloud altitudes $h_{ \pm}$with $\chi^{2}\left(h_{ \pm}\right)=2^{*} \chi_{\min }^{2}$. The procedure allows the determination of SVC opacity and altitude with an error estimate. 


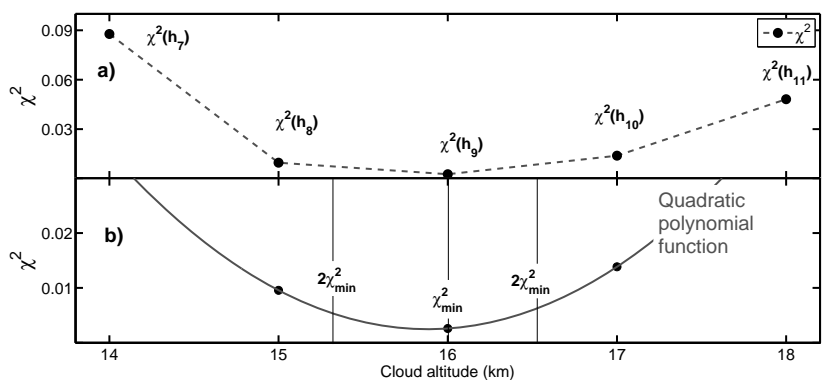

Figure 12. (a) Distribution of $\chi^{2}$ with the cloud altitude $\left(h=h_{n}\right.$, $n=7, \ldots, 11 ; h_{7}=14 \mathrm{~km}, h_{8}=15 \mathrm{~km}, h_{9}=16 \mathrm{~km}, h_{10}=17 \mathrm{~km}$ and $h_{11}=18 \mathrm{~km}$ ) for a sub-visual cirrus cloud observed on 18 January 2005. The distribution of $\chi^{2}$ with cloud altitude is represented only for five values of cloud altitude of the LUT grid in order to facilitate the interpretation of the figure. (b) Quadratic polynomial function (grey solid line) calculated from $h_{8}, h_{9}, h_{10}, \chi^{2}\left(h_{8}\right)$, $\chi^{2}\left(h_{9}\right)$ and $\chi^{2}\left(h_{10}\right)$ (black dots). The cloud altitudes $h_{ \pm}$with $\chi^{2}\left(h_{ \pm}\right)=2^{*} \chi_{\min }^{2}$ are 15.33 and $16.43 \mathrm{~km}$, and hence in this case the cloud altitude $=[16-0.67 \mathrm{~km}, 16+0.43 \mathrm{~km}]$.

\section{Results and discussion}

\subsection{Daily mean AOD}

The time series for the entire campaign are displayed in Fig. 13, where ODS AODs are represented by black dots with error bars and AERONET AODs at $370 \mathrm{~nm}$ by squares. AERONET AODs at $370 \mathrm{~nm}$ were calculated using the Ångström exponent values provided by AERONET for those days of measurements. ODS error bars represent the asymptotic standard parameter error, and the grey dashed line is the relative error that is defined as

$\mathrm{RE}=\frac{\mathrm{AOD}_{\mathrm{ODS}}-\mathrm{AOD}_{\mathrm{AERONET}}}{\mathrm{AOD}_{\mathrm{AERONET}}}$.

Some data are missing because of power failure or the presence of thick clouds during the full day not allowing AOD determination. Most ODS and AERONET AOD values are consistent within ODS error bars. The AOD is highly variable, displaying sometimes minima of about 0.2 in December-February and episodic strong Saharan dust increases for a few days up to 1.2 during the winter dry season. An increase of the ODS error bars is found for those dusty days, suggesting short-term dust episodes. As expected, many more data are missing and the error bars increase during the monsoon rainy season (May-September) due to the frequent presence of thick clouds inhibiting the measurements during the whole day or at least part of the day. Low AOD values during this period are due to dust cleaning by rainfall.

Figure 14a shows the correlation between all ODS and AERONET AODs. Both instruments present a reasonable agreement according to the correlation coefficient with a value of 0.77 , although they show some scatter on the plot.
The scatter would mainly arise from two sources. Firstly, note that there are few points for high AOD values where the differences between both instruments are significant higher. This result can be explained by the increase of ODS error bars with the aerosol load, since the deviation of daily mean AOD is high for the dusty episodes. Secondly, ODS retrievals during cloudy periods have higher errors with respect to retrievals for the cloud-free days. For limiting the perturbation of the measurements by clouds, a similar analysis was carried out but considering the cloud-free days only. As shown in Figs. 5 and 8b, the presence of clouds implies fast variations in ODS signals; therefore a day is classified as cloudfree if the ODS signals for SZA < at least $58^{\circ}$ (roughly from 08:00 to 16:00 UTC) do not present these fast variations. Examples of cloud-free days are shown in Figs. 4 and 8a. For the whole data set, $40 \%$ of the days were classified as cloudfree days, whose correlation plot is shown in Fig. 14b. The correlation improves to 0.94 , but the slope indicates a slight underestimation of ODS AOD by $17 \%$ during high-dust-load episodes. The mean bias error (MBE) and the mean absolute bias error (MABE) were calculated for the two data sets using the following expressions:

$$
\begin{aligned}
& \mathrm{MBE}=100 \cdot \frac{1}{N} \sum_{i=1}^{N} \frac{\operatorname{AOD}_{\mathrm{ODS}}(i)-\operatorname{AOD}_{\mathrm{AERONET}}(i)}{\operatorname{AOD}_{\mathrm{ODS}}(i)}, \\
& \mathrm{MABE}=100 \cdot \frac{1}{N} \sum_{i=1}^{N} \frac{\left|\operatorname{AOD}_{\mathrm{ODS}}(i)-\operatorname{AOD}_{\mathrm{AERONET}}(i)\right|}{\operatorname{AOD}_{\mathrm{ODS}}(i)},
\end{aligned}
$$

where $\mathrm{AOD}_{\mathrm{ODS}}$ and $\mathrm{AOD}_{\mathrm{AERONET}}$ are the $\mathrm{AOD}$ retrieved by ODS and AERONET, respectively, and $N$ is the number of data. The uncertainty of MBE and MABE is estimated by the standard error (SE) defined as follows:

$\mathrm{SE}=\frac{\mathrm{SD}}{\sqrt{N}}$,

where SD represents the standard deviation. The values of MBE and MABE for the whole data set are $(-15.4 \pm 0.9)$ and $(20.4 \pm 0.7) \%$, respectively, while considering only the cloud-free days $(-16.1 \pm 0.9)$ and $(16.5 \pm 0.9) \%$. Note that the negative sign of MBE means that ODS measurements underestimate on average the AERONET measurements. The values of SE indicate stable behavior of MBE and MABE. However, results show that the presence of clouds during the day has a significant impact on the AOD retrievals. Firstly, in the presence of clouds the contrast between scattered and total sunlight is reduced. Secondly, the presence of clouds reduces the amount of reliable data during the day, and hence the errors in AOD retrievals increase. We observe also in Fig. 14 a larger underestimation of ODS measurements with respect to AERONET for AOD values larger than 0.8. The main reason for this is the strong AOD variability during dust storms. While the daily average AERONET AOD is the mean 

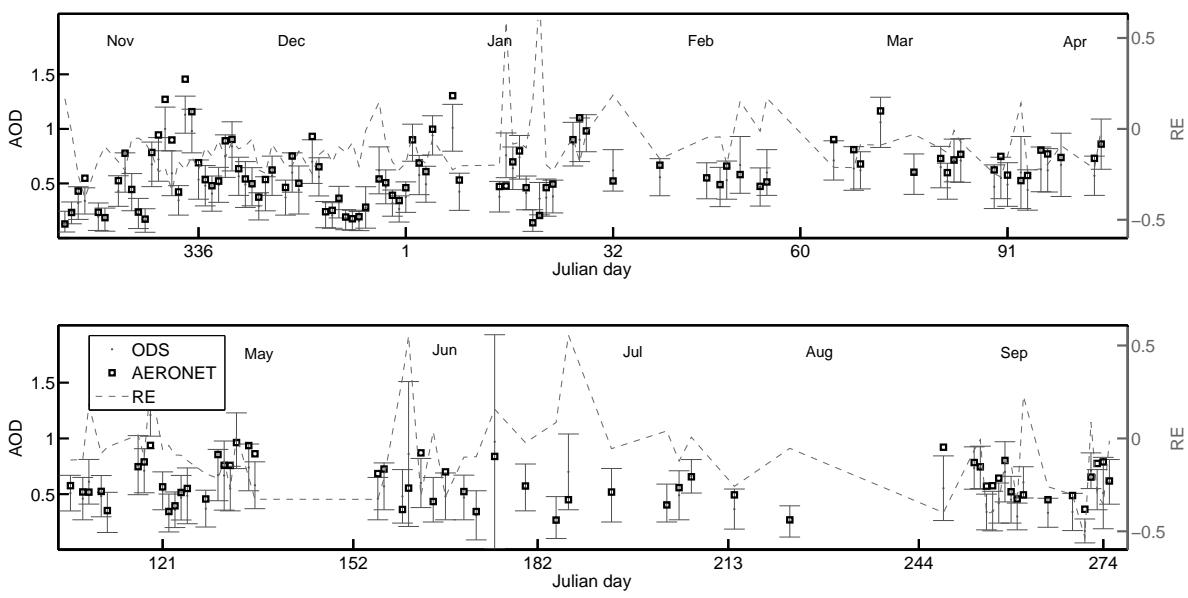

Figure 13. AOD derived from ODS blue channel (grey dots with error bars) and AERONET (squares) at $370 \mathrm{~nm}$ between November 2004 and October 2005. The grey dashed line represents the relative error that is defined in Eq. (4).

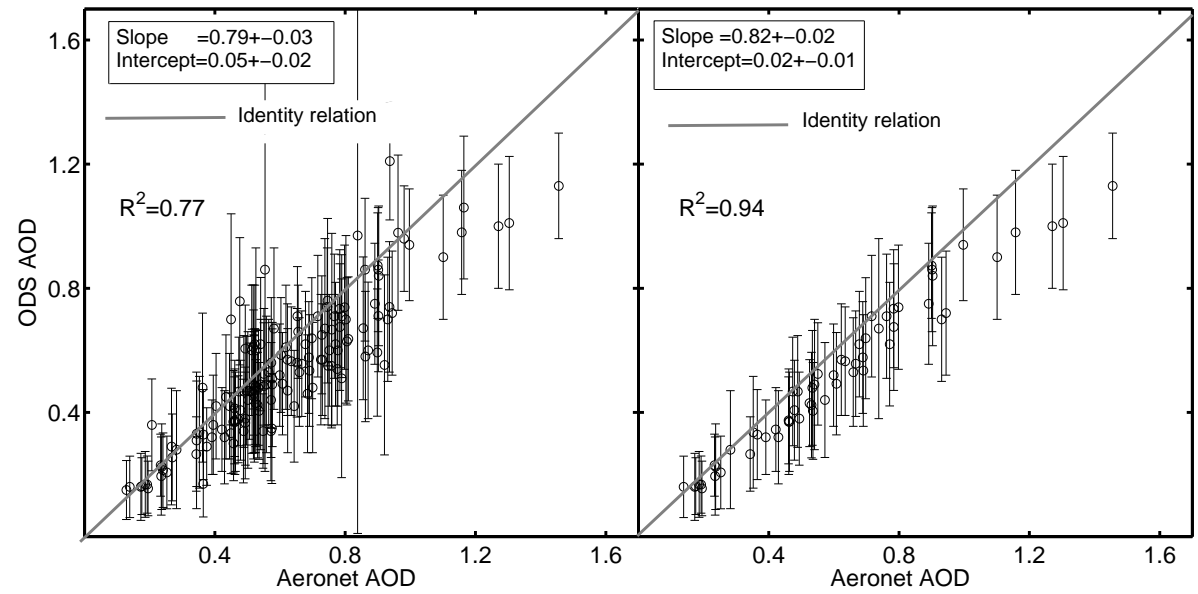

Figure 14. (a) Correlation between ODS blue channel and AERONET AOD at $370 \mathrm{~nm}$ for the whole data set, where the ODS error bars represent the asymptotic standard parameter. (b) Same as (a) but for cloud-free days only.

of instantaneous measurements during the day, the ODS estimation corresponds to the AOD value that provides the best fit between simulations and the observations acquired during the whole day. For days of high AOD variability, ODS and AERONET might be thus very different. In order to validate this result, we calculated the daily standard deviation of AERONET AOD measurements for the data illustrated in Fig. 14b, and where we found a daily standard deviation of AERONET AOD measurements 2 times bigger on average for the days of AOD higher than 0.8. Since such an increase in the AOD variability could imply differences between the measurements of both instruments, two half-day AOD ODS values have been retrieved for days of AOD larger than 0.8, in the morning from 07:30 to 12:00 UTC and the afternoon from 12:00 to 16:30 UTC. In this way, the standard deviation of AERONET AOD measurements is reduced by nearly half of the initial value, and thus the correlation between instru- ments must improve. Fig. 15a shows an example of the ODS blue-signal evolution on 5 January 2005 and those simulated for the two AOD values retrieved using half-day signal only. A similar analysis to that shown in Fig. 14 was performed for this case of two AOD values larger than 0.8. The correlation between AERONET and ODS is shown in Fig. 15b, where the $R^{2}$ coefficient improves to 0.97 , and the MBE and MABE parameters to $(-13.82 \pm 0.9)$ and $(15.01 \pm 0.7) \%$, respectively. In addition, for each estimated AOD we calculated the root mean square error in order to evaluate the goodness of the fit. We found a value of 0.013 on average and a standard deviation of 0.003 . Despite the AOD underestimation the results show that ODS measurements are reliable over a large range of AOD.

The next step in this analysis is to study the influence of absorbing of desert dust on the retrieval procedure. To this end, we have simulated first the blue ODS signal using a 

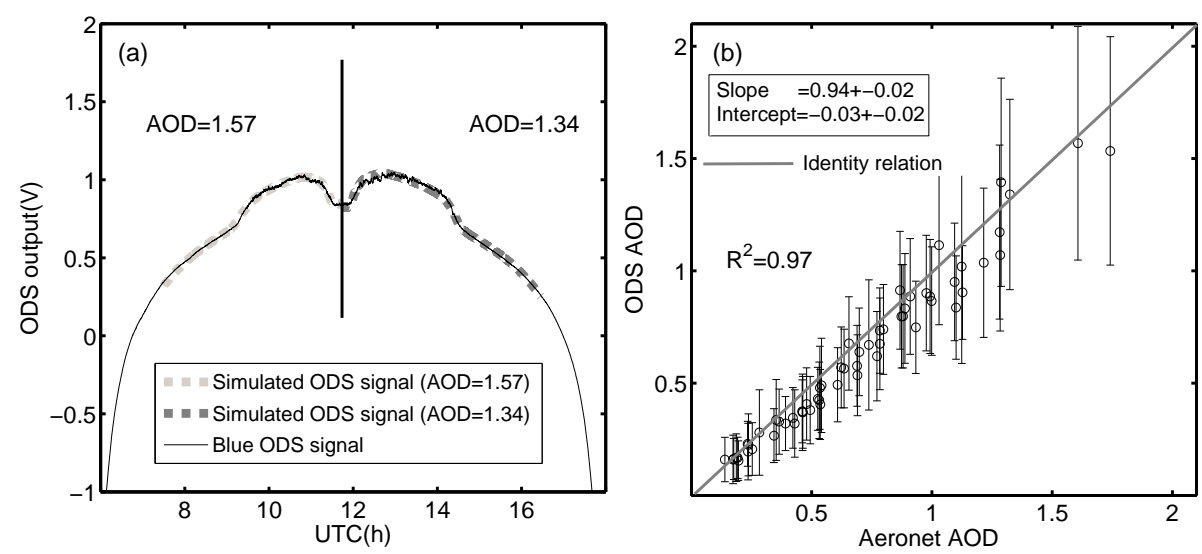

Figure 15. (a) Evolution of ODS signal measured on 5 January 2005 and those simulated for the AOD values obtained by the retrieval procedure of dust opacity using only half of the day. (b) Correlation between ODS blue channel and AERONET AOD at $370 \mathrm{~nm}$ for cloudfree days, and where two values of AOD per day have been estimated for days with a daily average AOD above 0.8 .

value of the single-scattering albedo of $\omega=0.8$ and a total opacity $\mathrm{AOD}=0.4$. Subsequently we have added a random noise to the signal with an amplitude of $3 \%$. This is the test signal and is supposed to be the ODS measurement. Finally we have calculated the contour lines of chi squared $\left(\chi^{2}\right)$ in the AOD- $\omega$ space according to the follows expression:

$\chi^{2}=\frac{1}{n} \sum_{i=1}^{n}\left(O_{\text {test }}(i)-O_{\text {sim }}(i)\right)^{2}$,

where $O_{\text {test }}$ is the test signal, $O_{\text {simul }}$ is the simulated ODS signal in the AOD- $\omega$ space and $n$ is the number of observations. Figure 16 shows the contour lines of $\chi^{2}$ and where, as was expected, the minimum is found for $\omega=0.8$ and $\mathrm{AOD}=0.4$. The estimation of AOD by assuming a constant value of $\omega=\omega^{*}$ is given by the intersection between the horizontal line at $\omega=\omega^{*}$ and the contour line with a minimum value of $\chi^{2}$. In the example shown in Fig. 16, the AOD estimated for a constant value of $\omega=0.85$ is 0.36 , whereas for $\omega=0.90$ this parameter takes a value of 0.34 . Therefore, by assuming a constant value of $\omega=0.90$ in our model, the errors made in the estimation of AOD are smaller or equal to $15 \%$ of $\mathrm{AOD}$ as long as the single-scattering albedo of dust aerosols is not smaller than 0.8 . Note that this error is within the bias error estimated in the comparison with AERONET.

Finally, the AOD has been retrieved from nighttime ODS red-channel measurements during moon periods in November-March and June. Results are presented in Fig. 17 as well as the AOD values provided by AERONET at $870 \mathrm{~nm}$ at 16:00 and 07:00 UTC of the next day for each ODS measurement. By comparing each AOD retrieved by ODS during the night with those provided by AERONET at 16:00 and 07:00 UTC of the next day, strong AOD increases are observed on some days at night followed by a decrease in the morning. Since nighttime AERONET and ODS measurements are separated by about $4-7 \mathrm{~h}$, it is clear that the aerosol load can change strongly from one measurement to the other.

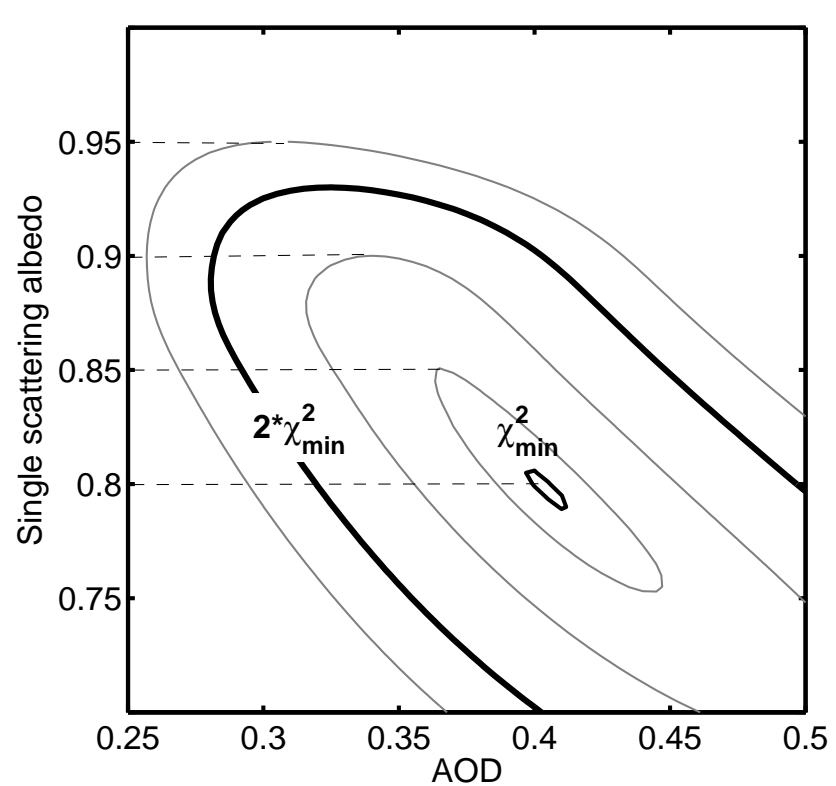

Figure 16. Contours of $\chi^{2}$ in the AOD- $\omega$ space for the ODS test signal. The minimum of $\chi^{2}$ is found for $\mathrm{AOD}=0.4$ and $\omega=0.8$.

Strong changes in AERONET aerosol load were frequently observed within 3-6h, consistent with the differences between ODS and AERONET data. A better understanding of AOD change might be provided by simultaneous ODS and lidar measurements.

\subsection{Cloud altitude and COD}

Cloud altitudes and opacities were estimated by using ODS measurements at sunrise and sunset by using the retrieval procedure described in Sect. 3.4. A total of $71 \mathrm{SVCs}$ were detected: 40 at sunrise and 31 at sunset. COD and cloud altitude retrieved for those 71 cases are shown in Fig. 18. The grey 

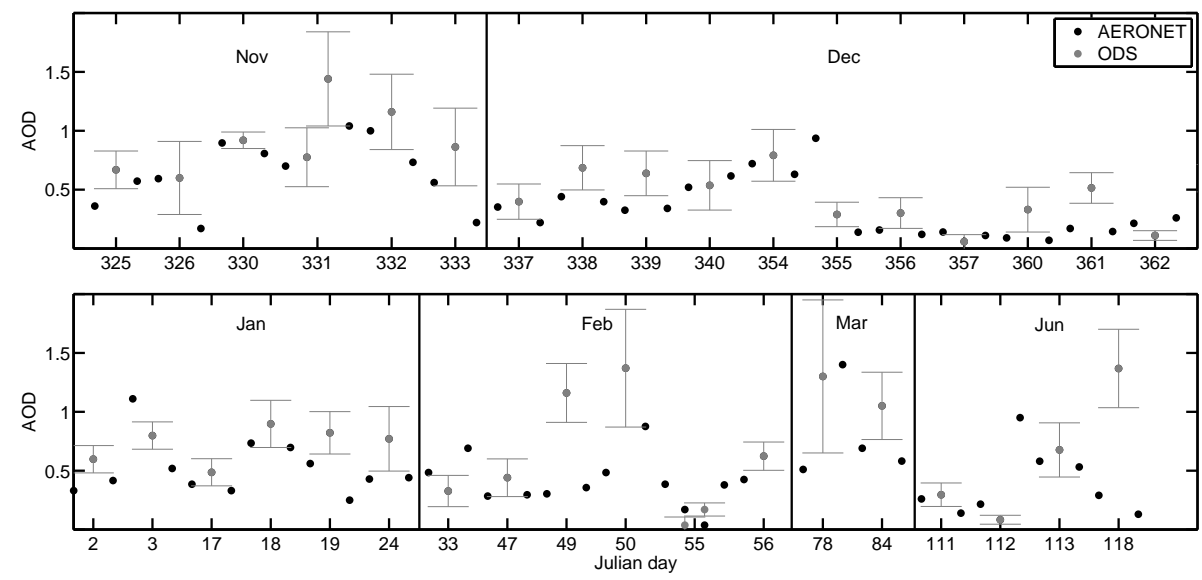

Figure 17. AOD derived from ODS red channel at nighttime (grey dots with error bars) between November 2004 and October 2005 , and AERONET AOD (black dots) at 870 nm at 16:00 and 07:00 UTC of the next day for each ODS measurement.

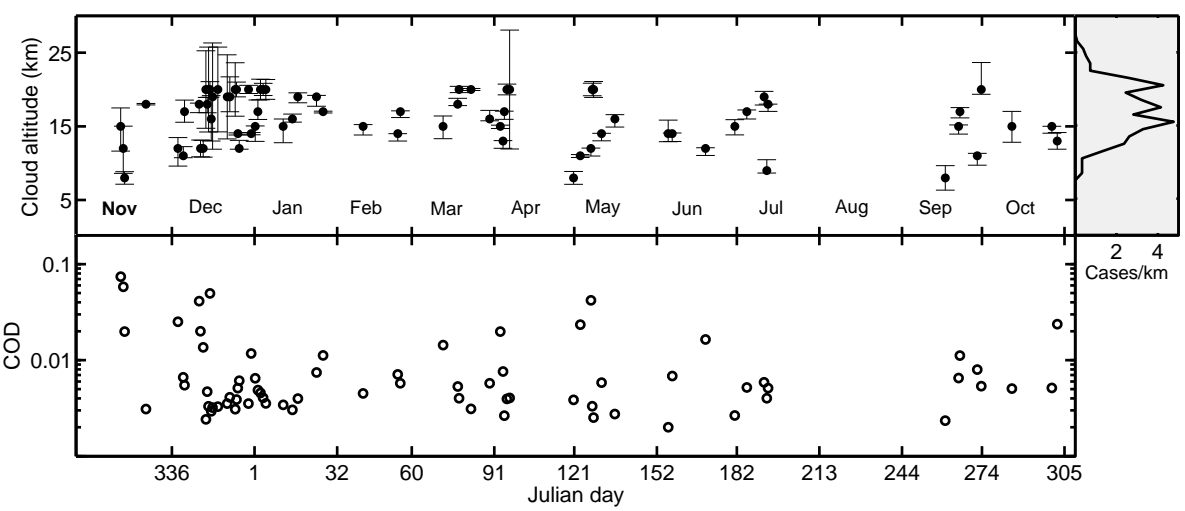

Figure 18. Retrieved cloud altitudes (upper panel) and COD (lower panel) between November 2004 and October 2005. The grey panel on the right shows the histogram of cloud altitude $\left(\right.$ cases km$\left.{ }^{-1}\right)$.

panel on the right of Fig. 18 shows the histogram of cloud altitude (cases $\mathrm{km}^{-1}$ ), where each case is weighted by the errors of the estimated altitude. That is to say, if the estimated altitude is $h^{*}$ with errors $h_{ \pm}$, then $1 /\left(h_{+}+h_{-}\right)$is the contribution of this case for altitudes within $\left(h^{*}-h_{-}, h^{*}+h_{+}\right)$. SVC clouds are more frequent between 14 and $20 \mathrm{~km}$, that is, at or above the tropopause level. This result is consistent with the altitude of the minimum temperature at $18 \mathrm{~km}$ reported by the temperature soundings at Ouagadougou airport. Their frequency of occurrence is maximal between December and January. In some cases SVCs can be as high as $18-20 \mathrm{~km}$. However it is unclear if these altitudes are significant because of the large $\pm 5 \mathrm{~km}$ uncertainty on their altitude due to their extremely thin optical opacity. Some SVCs (about $9 \%$ ) also occur below $12 \mathrm{~km}$ - useful information because most satellite analyses only sample SVC at higher altitudes. Regarding optical depth, it is clear that ODS twilight measurements offer the unique capacity to detect SVCs as thin as $10^{-3}$ at twilight, that is, far thinner than, for instance, the CALIPSO lidar detection capacity.

\section{Conclusions}

In this paper we have demonstrated the capabilities of ODS to retrieve the daily average AOD and the optical depth and altitude of sub-visual clouds. The procedure used to retrieve the AOD is based on the change observed between the scattered sunlight at zenith and the sum of direct and scattered sunlight when the sun is passing within the FOV of the instrument. The retrieval procedure is based on the use of radiative transfer simulations to reproduce the signals observed by the instrument. ODS measurements performed between November 2004 and October 2005 in the northern tropics in Ouagadougou in Burkina Faso in western Africa have been compared to those of an AERONET CIMEL deployed at the same location. Taking into account cloud-free days only, a 0.94 correlation is found between the measurements of the two instruments, whereas the correlation degrades to 0.77 when including cloudy days in the comparison. The AOD in Ouagadougou is found to be highly variable, ranging between 0.1 and 1.7, displaying strong maxima during Saharan 
dust storms. Under such conditions, we found it necessary to retrieve two AOD values per day for days of AOD larger than 0.8 . The results also demonstrate the capability of ODS for AOD retrieval during the night when the moon crosses the ODS FOV, allowing the AOD investigation during the whole day. However, about $30 \%$ of ODS nighttime measurements show large differences with AERONET at 07:00 and 16:00 UTC, differences which might indicate nighttime AOD variations related to wind velocity changes. However such study requires additional measurements, such as lidar and winds to validate the ODS nighttime retrieval procedure and to explore the potential AOD diurnal changes.

The ODS measurements available in Ouagadougou also demonstrate its capability to retrieve the opacity and altitude of SVCs during sunrise and sunset. As for AOD, these parameters are retrieved by using radiative transfer simulations but in this case at twilight. The procedure is shown to allow the detection of extremely thin SVCs of optical thickness ranging from 0.002 to 0.08 , far thinner than the CALIPSO lidar detection limit. In addition it is shown that the cloud particle phase function has little impact on the retrievals, as well as the surface albedo and the cloud geometrical thickness. Overall, $69 \%$ of SVCs detected by ODS are found at altitudes higher than $14 \mathrm{~km}$, that is, at or above the tropopause. In terms of the optical thickness, the SVC clouds at high altitudes seem to be thinner than clouds at lower altitudes; however, it is important to emphasize that a quantitative description of this relation between the altitude and opacity of SVC clouds is complicated due to the errors associated with the cloud altitude. In this regard, these retrievals need to be verified against lidar measurements in order to fully analyze the potential of these measurements. This comparison would allow us to better understand the limitations of the retrieval procedure as well as to identify the different error sources.

Acknowledgements. We thank the AERONET team, especially the PI Didier Tanré as well as the staff for establishing and maintaining the AERONET site.

Edited by: M. Penning de Vries

\section{References}

Dubovik, O., Holben, B., Eck, T. F., Smirnov, A., Kaufman, Y. J., King, M. D., Tanré, D., and Slutsker, I.: Variability of Absorption and Optical Properties of Key Aerosol Types Observed in Worldwide Locations, J. Atmos. Sci., 59, 590-608, 2002.

Dubovik, O. and King, M. D.: A flexible inversion algorithm for retrieval of aerosol optical properties from Sun and sky radiance measurements, J. Geophys. Res., 105, 20673-20696, doi:10.1029/2000JD900282, 2000.

Evans, K. F.: The spherical harmonics discrete ordinate method for three-dimensional atmospheric radiative transfer, J. Atmos. Sci., 55, 429-446, 1998.
Hao, W. M. and Liu, M.-H.: Spatial and temporal distribution of tropical biomass burning, Global Biogeochem. Cy., 8, 495-503, 1994.

Hartmann, D. L., Holton, J. R., and Fu, Q.: The heat balance of the tropical tropopause, cirrus, and stratospheric dehydration, Geophys. Res. Lett., 28, 1969-1972, 2001.

Hess, M., Koepke, P., and Schult, I.: Optical properties of aerosols and clouds: the software package OPAC, B. Am. Meteorol. Soc., 79, 831-844, 1998.

Heymsfield, A. J.: Ice particles observed in a cirriform cloud at $-83^{\circ} \mathrm{C}$ and implications for polar stratospheric clouds, J. Atmos. Sci., 43, 851-855, 1986.

Holben, B. N., Eck, T. F., Slutsker, I., Tanré, D., Buis, J. P., Setzer, A., Vermote, E., Reagan, J. A., Kaufman, Y. J., Nakajima, T., Lavenu, F., Jankowiak, I., and Smirnov, A.: AERONET - a federated instrument network and data archive for aerosol characterization, Remote Sens. Environ., 66, 1-16, 1998.

Hsu, N. C., Herman, J. R., Torres, O., Holben, B. N., Tanre, D., Eck, T. F., Smirnov, A., Chatenet, B., and Lavenu, F.: Comparisons of the TOMS aerosol index with Sun-photometer aerosol optical thickness: results and applications, J. Geophys. Res., 104, 6269-6279, doi:10.1029/1998JD200086, 1999.

Jacobson, M. Z.: Global direct radiative forcing due to multicomponent anthropogenic and natural aerosols, J. Geophys. Res., 106, 1551-1568, doi:10.1029/2000JD900514, 2001.

Jensen, E. J., Pfister, L., Bui, T. V., Lawson, P., Baker, B., Mo, Q., Baumgardner, D., Weinstock, E. M., Smith, J. B., Moyer, E. J., Hanisco, T. F., Sayres, D. S., Clair, J. M. St., Alexander, M. J., Toon, O. B., and Smith, J. A.: Formation of large $(\simeq 100 \mu \mathrm{m})$ ice crystals near the tropical tropopause, Atmos. Chem. Phys., 8 , 1621-1633, doi:10.5194/acp-8-1621-2008, 2008.

Jensen, E. J., Diskin, G., Lawson, R. P., Lance, S., Bui, T. P., Hlavka, D., McGill, M., Pfister, L., Toon, O. B., and Gao, R.: Ice nucleation and dehydration in the Tropical Tropopause Layer, P. Natl. Acad. Sci. USA, 110, 2041-2046, 2013.

Lawson, R. P., Pilson, B., Baker, B., Mo, Q., Jensen, E., Pfister, L., and Bui, P.: Aircraft measurements of microphysical properties of subvisible cirrus in the tropical tropopause layer, Atmos. Chem. Phys., 8, 1609-1620, doi:10.5194/acp-8-1609-2008, 2008.

Liou, K.-N.: Influence of cirrus clouds on weather and climate processes: a global perspective, Mon. Weather Rev., 114, 11671199, 1986.

Lynch, D. K., Sassen, K., Starr, D. O., and Stephens, G.: Cirrus, Oxford Univ. Press, New York, USA, 480 pp., 2002.

Maria, J.-L., Trân, T. T., Pommereau, J.-P., Rannou, P., Malique, C., Correia, J. J., and Porteneuve, J.: Technical aspect of the optical depth sensor, Adv. Space Res., 38, 726-729, 2006.

McFarquhar, G. M., Heymsfield, A. J., Spinhirne, J., and Hart, B.: Thin and subvisual tropopause tropical cirrus: observations and radiative impacts, J. Atmos. Sci., 57, 1841-1853, 2000.

Miller, R. L. and Tegen, I.: Climate response to soil dust aerosols, J. Climate, 11, 3247-3267, 1998.

Mishchenko, M. I.: Light scattering by randomly oriented axially symmetric particles, J. Opt. Soc. Am. A, 8, 871-882, doi:10.1364/JOSAA.8.000871, 1991.

Mishchenko, M. I. and Travis, L. D.: T-matrix computations of light scattering by large spheroidal particles, Opt. Commun., 109, 16$21,1994$. 
Pollack, J. B. and Cuzzi, J. N.: Scattering by nonspherical particles of size comparable to wavelength - a new semi-empirical theory and its application to tropospheric aerosols, J. Atmos. Sci., 37, 868-881, doi:10.1175/15200469(1980)037<0868:SBNPOS>2.0.CO;2, 1980.

Ramanathan, V., Cess, R. D., Harrison, E. F., Minnis, P., Barkstrom, B. R., Ahmad, E., and Hartmann, D.: Cloud-radiative forcing and climate: results from the Earth radiation budget experiment, Science, 243, 57-63, 1989.

Sarkissian, A., Pommereau, J. P., and Goutail, F.: Identification of polar stratospheric clouds from the ground by visible spectrometry, Geophys. Res. Lett., 18, 779-782, 1991.

Sassen, K.: Indirect climate forcing over the western US from Asian dust storms, Geophys. Res. Lett., 29, 103-1-103-4, 2002.

Stamnes, K., Tsay, S. C., Wiscombe, W., and Jayaweera, K.: Numerically stable algorithm for discrete-ordinate-method radiative transfer in multiple scattering and emitting layered media., Appl. Opt., 27, 2502-2509, doi:10.1364/AO.27.002502, 1988.
Tegen, I., Lacis, A. A., and Fung, I.: The influence on climate forcing of mineral aerosols from disturbed soils, Nature, 380, 419422, 1996.

Toledo, D.: Preparation and validation of the cloud and dust opacity sensor ODS for ExoMars 2018 mission, $\mathrm{PhD}$ thesis in Astrophysics, University of Reims Champagne-Ardenne, 2015.

Trân, T. T., Pommereau, J.-P., Rannou, P., and Maria, J.-L.: Scientific aspects of the optical depth sensor, Adv. Sp. Res., 36, 21822186, 2005.

Trân, T.-T.: Optical depth sensor for measurement of dust and clouds in the atmosphere of Mars: radiative transfer simulations and validation on earth., Thèse Dr. (Astrophysique), Univ. Versailles St-Quentin en Yvelines, 2005.

Wang, P.-H., Minnis, P., McCormick, M. P., Kent, G. S., and Skeens, K. M.: A 6-year climatology of cloud occurrence frequency from Stratospheric Aerosol and Gas Experiment II observations (1985-1990), J. Geophys. Res., 101, 29407-29429, doi:10.1029/96JD01780, 1996. 